\title{
Factors Impacting Crisis Preparedness At Airports
}

\author{
Mansoor Khalfan Almansoori \\ Lincoln University College Address UAE Dubai \\ almansoori1@live.com
}

Received date: 28 June 2018; Accepted date: 9 July 2018; Published date: 19 October 2018

Academic Editor: Haslinda Abdullah

Copyright (@ 2018. Mansoor Khalfan Almansoori . Distributed under Creative Commons CC-BY 4.0

\begin{abstract}
The study below describes the factors that affect the emergency preparedness at airports. The report below describes three main factors that play a significant role in the maintenance of emergency preparedness at airports. The main objectives of the study are to determine the impact of staff education and training, information technology and MDC operations on the crisis preparedness at airports. The main factors that were found to influence crisis management at airports were - public awareness and training of the staff, MDC operations and planning and information management and communication. The role of these factors has been validated by the study of previously established literature in the field of emergency preparedness at airports. The results are discussed on the basis of the literature review and recommendations have been made at the end. The findings suggest that MDC helps in disaster management through a number of sequential steps. The staff needs to be trained effectively for achieving the best results.
\end{abstract}

Keywords: Crisis preparedness, Airports, Factors influencing crisis preparedness

\section{Introduction}

Crisis preparedness or emergency preparedness can be described as the continuous cycle including planning, training, organizing, exercising, equipping and evaluating the activities that ensure protection, prevention, response, recovery and mitigation against terrorist activities, natural disasters and manmade disasters. It

Cite this Article as: Mansoor Khalfan Almansoori (2018)," Factors Impacting Crisis Preparedness at Airports", The Journal of Organizational Management Studies, Vol. 2018 (2018), Article ID 824277, DOI: 10.5171/2018. 824277 
is a dynamic process and calls for the contribution of all the layers of the government. It also requires the coordination between governments, NGOs and private sectors. The main motives of this process are the identification of threats, determination of vulnerabilities and identification of the resources that are required for managing the crises at the airports. There is a need to establish indicators for early detection of crisis at airports (Drljača, 2017).

Emergency preparedness is a global challenge in the current scenario and this can be witnessed in the form of a large number of tragedies that occur globally. The main reason for this can be the fact that airports differ from each other in terms of complexities. Some airports are small with uncomplicated facilities and they are usually found in small cities and towns. Others are large sized airports that are found in metropolitan cities and consist of several commercial installations. Some Airports are operated by the state while some are managed by the local governments (Drljača, 2017). There is no airport in the real world that possesses all the resources to respond to each and every emergency situation in an independent manner. Surrounding communities play an important role in providing the airport with the required resources for emergency preparedness. If any strong emergency preparedness program is not prepared for airports, it can lead into huge damage, including post emergency issues and liabilities. The report below will give an account of the factors that influence the emergency preparedness at airports. The main factors that can be thought to have an impact on crisis preparedness at airports are information management and communication, role of management, public education and staff training and rehearsals (Meshack, 2013). The effect of these factors in the management of a crisis at the airports will be studied in details in due course of the research. The research will be based on the review of secondary literature. The research findings of the previous researchers related to this topic will be analyzed to fulfill the given objectives of the study.

\section{Research objectives}

The objectives on which the given research will be based on are-

- To examine the effect of information management and communication on the disaster preparedness at airports.

- To analyze the effect of staff training and public education on the crisis preparedness at airports.

- To determine the impact of the Management, Direction and Coordination (MDC) on the disaster preparedness at airports.

This study will be highly significant in context of the UAE, and will help in determining the strengths and weaknesses of disaster preparedness capabilities followed by the airports currently.

\section{Literature Review}

\section{Elements and dimensions of disaster preparedness}

There are a large number of dimensions that affect the crisis preparedness at airports. The dimensions of preparedness can be described as the goals which are intended to be achieved by the preparedness. There are basically eight dimensions of preparedness that need to be taken care of in the times of crisis by airports; MDC, hazard knowledge, life safety protection, informal and formal response agreements, acquisition of resources, coping with emergency and restoration of the main functions and initiating recovery activities. People must be given knowledge about the following- health and safety operations, critical infrastructure as well as facilities, continuity of operations after the disasters at airports and service delivery (Vincent, 2017). 


\section{Communication and Information Management}

For carrying out the correct operations of preparedness at airports, there is a need for setting up the proper conversation and providing accurate and timely information before, during and after the disasters. The National Societies play a significant role in providing responses at the time of natural disasters. They must develop procedures as well as mechanisms for obtaining and analyzing the warning information in relation to the hazards. The information needs to be correctly transferred between different levels of the response team to manage the safety at airports (Smith, 2016).

Emergency communication is also an important factor affecting the emergency preparedness at airports. It refers to the exchange of information through videos, voice and data to fulfill the emergency recovery missions. Communications are required in an emergency operation to ensure proper management of the crisis management activities, maintaining situational awareness and establishing control and command. The use of information technology is needed in planning emergency responses for situations at the airport to maintain better communication between emergency services (Rapan, et al., 2017). Communications at the time of emergency at the airports can be divided into three types-

Operability - It includes the ability of the emergency responders to sustain communications during the mission operations.

Continuity of communications - This type of communication can be defined as the one used by agencies for emergency response to manage the communication in cases of infrastructural damage during the crisis.

Interoperability - It exhibits the ability of the responders in case of an emergency to communicate among various disciplines, levels of the government and jurisdictions. They use a wide range of frequency bands to maintain speedy communication between the defined people. Proper communication is necessary for organizations managing the crisis, for coordinating their operations and managing the situations in the best possible manner. A common Information Space (CIS) can be used by organizations to manage the operations (Pérez, et al., 2017).

\section{Management, Direction and Coordination (MDC)}

This dimension of disaster preparedness deals with the identification of the lines of responsibility and authority and management of the resources that will be utilized in case of the emergency. The MDC dimension also takes into account the activities designed for effective management of the disasters. It includes training, exercises, drills as well as educational activities for the members of the staff and the public. The local agencies for the crisis management use the National Incident Management System (FEMA, 2017). This system describes the roles and responsibilities of people in the incident management team to carry out emergency operations in an effective manner. For ensuring proper management of disasters, proper coordination and mutual trust needs to be maintained among the agencies and people involved in the emergency operations' team. Coordination of the activities between local community based organizations, NGOs, government troops, airport staff and the affected population is needed to make sure that a large number of people can be provided with assistance at the time of the disaster in a short period of time. If these approaches of disaster preparedness are developed before the disaster hits, maximum number of people can be saved and the damage can be reduced to a minimum (Miller \& Rivera, 2016).

MDC responses are mainly related to the development of response teams and 
maintaining the synchronization between them. It also arranges the provision for training and development of the staff and recovery teams. For maintaining MDC operations, the ICAO has made it mandatory for airports to implement safety management system (SMS) programs to ensure safety of the passengers and crew at the airports (Stolzer, 2017).

\section{Public Education, Staff Training and Rehearsals}

According to Muchelule and Mulama (2016), training programs and rehearsals for the staff of the airports as well as the response teams and public education campaigns are needed to be incorporated for ensuring disaster preparedness, which many airports still lack. The main aim for this program is to develop a community of alert, self reliant and informed people so that they can play significant roles during disaster recovery and cooperate with government officials in managing the crisis situations at airports (Muchelule \& Mulama, 2016). After the training, mock drills and rehearsals are equally important. The rehearsals help in the identification of the gaps that may be otherwise overlooked. Rehearsals help in the stimulation of the rescue and search operations, coordination between the different rescue teams, provisions for first aid, relief logistics and transport and such other aspects of the crisis management at airports (Muchelule \& Mulama, 2016).

Disaster preparedness is not entirely the work of experts and emergency responders from the government disaster organizations or National societies. Organizations, citizens and the local volunteers also have a significant role to play before, during and after the disasters. The local populations are the first to get hit by the disasters in any area. National societies help in the rescue activities and provide emergency relief and treatment to the families. They also help in providing education and training to the people related to first aid and emergency treatment. Community Based Disaster
Preparedness (CBDP) is the process that needs to be developed and implemented for risk reduction and disaster preparedness (Drishti Publications , 2015).

This factor is very important as it relates to the creation of awareness among the public as they are the first ones to deal with the disasters. The staff and recovery teams also need to be well trained to help people in providing them assistance.

\section{Research Design and Methodology}

Research methodology includes methods used for successful conduction of the research. For conducting a research, the most important part is the collection of data. There are two methods for the collection of data for the research namely; primary data and secondary data. The primary data is the firsthand data and is collected directly from the respondents. The secondary data, on the other hand, is collected from the study of previously established literature in the form of reports, journal articles, books and so on (Hair Jr, et al., 2015).

In this research, we have used the secondary method for data collection. The data has been collected from journal articles, books and reports published by the experts in the area of crisis preparedness at airports. The reason behind choosing the secondary approach for data collection is that this method is quite reliable as the researches from which the extracts are retrieved, are already authorized and validated. The other reason is that the secondary research saves a great deal of time and cost (Bryman, 2016). Using these sources of secondary data, the literature review has been developed on the basis of previous researches that have been done on the same or related topics of factors affecting emergency preparedness at airports. The study of this literature review will help in providing information about what factors affect airport preparedness in the time of crisis and what is the level of their impact. 


\section{Results}

The study based on the literature review has provided deep insights about the factors that are responsible for managing the airport preparedness before, during and after the crisis. Through the study, it can be claimed that all the airports have emergency preparedness features that aim at reducing the damage due to any man made or natural disasters, accident or acts of terrorism to the minimum. The airports have well defined emergency communication plans to maintain coordination between different teams that operate during the crisis or recovery operations. They enhance the operability and interoperability during crisis management operations. MDC also plays a significant role in disaster management and helps in sequential planning of events that need to be done in the case of disasters. The staff needs to be trained for providing aid to the public during disasters and help the recovery teams to carry out the operations in a well-defined manner. The findings of the literature review suggest that many airports in small cities are still struggling with the development of a proper crisis preparedness plan.

\section{Discussion}

As per the literature review, the following objective-based information can be deduced:

Most airports possess a plan for emergency communication which helps them get a better control of the crisis situation through the maintenance of proper coordination between the recovery teams, government officials, airport staff and the public.There are basically eight dimensions of crisis management or disaster preparedness at the airports as mentioned in the literature review. These dimensions of disaster management are important and are necessary factors that affect the crisis preparedness at airports (Vincent, 2017).The information management helps the National Societies in conducting timely assessment of the availability of the responses and equipments in the time of need. It enhances the operability and interoperability of the operations in airport preparedness (Smith, 2016). The airports have well defined emergency communication plans to maintain coordination between different teams that operate during the crisis or recovery operations. Communication and information management are the two major factors that affect the crisis preparedness at airports. These factors allow the proper channeling of information between different layers of the response teams and helps in proper management of the crisis (Rapan, et al., 2017).

MDC plays an effective role in crisis management. The MDC dimensions are required by airports to provide guidance and direction to the people and the teams that are working during the time of crisis. They help in the identification of the lines of responsibility and authority for the recovery operations. They also help in maintaining the coordination between the management of the information, resources, equipments, human resources, public relations, logistics, and the environment at the time of the crisis (FEMA, 2017).

Staff training is the most critical part of emergency preparedness. The staff at most airports lacks the training and experience of disasters. This suggests that airports need to train the staff at priority basis to handle the crisis in an efficient manner. Staff training helps the employees at airports to be alert, self reliant and informed. Public awareness campaigns will help people to save themselves during disasters and reduce the damage to the minimum (IATA, 2016). These campaigns can be organized at airports during the waiting time for flights. The airport authorities need to undertake this with the help of various NGOs and the local governments to develop a plan for emergency preparedness.

\section{Study Limitations}

One of the major limitations of the study is the use of secondary research. The use of 
primary research would have provided latest and in-depth information.

\section{Conclusion and Recommendations}

The report gives an account of crisis management at airports. It discusses the impact of three factors- staff education and training, information technology and MDC operations on the crisis preparedness at airports. The impact of these three factors on emergency preparedness has been studied with the help of an extensive study of the previously established literature. The MDC operations affect airport preparedness in a positive manner as they provide directions to the people and teams working at the time of crisis management. Staff training is required to manage the people and operations of crisis management at airports. Information technology and communication helps in the management of operations properly and also helps in maintaining coordination between the teams.

The following recommendations can be made to improve the disaster preparedness at airports during the time of crisis:

- The airports must develop a policy for training and public awareness for ensuring proper disaster preparedness and its mitigation

- An integrated disaster management system needs to be developed at airports involving all the organizations that can serve to make air travel more secure.

- The stakeholders must conduct meetings at regular intervals to discuss the loopholes and make the emergency preparedness stricter and securer.

- For analyzing the robustness of the infrastructure enhancement projects, simulation modeling studies and capacity assessments must be performed effectively (Airsight, 2018).

\section{References}

1. Airsight (2018), 'Airport Planning,' [Online], [Retrieved July 07, 2018], https://www.airsight.de/consulting/airportplanning/

2. Bryman, A. (2016) Social Research Methods, Oxford University Press, Oxford, United Kingdom.

3. Drishti Publications (2015), 'Community Based Disaster Management,' [Online], [Retrieved July 07, 2018], http://www.drishtiias.com/upsc-exam-gsresources-COMMUNITY-BASED-DISASTERMANAGEMENT

4. Drljača, M. (2017) 'Anticipative Crisis Management at the Airport,' The National Academies of Sciences, Engineering, and Medicine, 37(5-6).

5. FEMA (2017), 'National Incident Management System,' [Online], [Retrieved July 07, 2018], https://www.fema.gov/media-librarydata/1508151197225ced8c60378c3936adb92c1a3ee6f6564/FINA L_NIMS_2017.pdf

6. IATA (2016), 'Crisis Communications in the Digital Age ,' [Online], [Retrieved July 07, 2018], https://www.iata.org/publications/Docume nts/social-media-crisis-communicationsguidelines.pdf

7. Hair Jr., J., Wolfinbarger, M., Money, A. and Samouel, P. (2015) Essentials of Business Research Methods, Routledge, London, England.

8. Meshack, A. A. T. (2013), 'Factors affecting disaster preparedness at Moi International Airport, Mombasa County, Kenya,' [Online], [Retrieved July 07, 2018], http://erepository.uonbi.ac.ke/bitstream/ha ndle/11295/90506/Amboka_Factors\%20aff ecting\%20disaster\%20preparedness $\% 20$ at $\% 20 \mathrm{Moi} \% 20$ International\%20Airport,\%20M ombasa\%20County,\%20Kenya.\%20.pdf?seq uence $=3$

9. Miller, D. S. \& Rivera, J. D. (2016), Community Disaster Recovery and Resiliency: Exploring Global Opportunities and Challenges, CRC Press, New York, United States of America.

Mansoor Khalfan Almansoori (2018), The Journal of Organizational Management Studies, DOI: $10.5171 / 2018.824277$ 
10. Muchelule, Y. \& Mulama, K. (2016), 'Factors Affecting Contingency Preparedness at Kisumu International Airport, Kisumu County, Kenya,' Journal for Studies in Management and Planning, 2 (2), 364-79.

11. Pérez, F. J., Zambrano, M., Esteve M., \& Palau C. (2017) 'A Solution for Interoperability in Crisis Management,' International Journal of Computers, Communications \& Control, 12 (4), 550-61.

12. Rapan, M., Štimac, I. \& Steiner, S. (2017), 'Implementation of IT systems for emergency management at the Zadar Airport,' [Online], [Retrieved July 07, 2018], https://bib.irb.hr/datoteka/872168.Implem entation_of_IT_Systems_for_Emergency_Man agement_at_the_Zadar_Airport.pdf
13. Smith, J. (2016), 'Regional Cooperation, Coordination, and Communication Between Airports During Disasters,' Transportation Research Record: Journal of the Transportation Research Board, 2177 (1), 132-40.

14. Stolzer, A. J. (2017), Safety Management Systems in Aviation, Routledge. 15. Vincent, A. (2017), 'EFSA 2017 Workshop on Crisis Preparedness,' [Online], [Retrieved July 07, 2018], https://www.efsa.europa.eu/sites/default/fi les/event/AF170608/AF170608-

p11b_EFSA\%20PLH\%20activities_G\%20Stan canelli.pdf 